\title{
User-Calibration of Fowler Ultra-Cal Mark III Digital Caliper
}

\author{
J. Estill
}

September 19, 1996

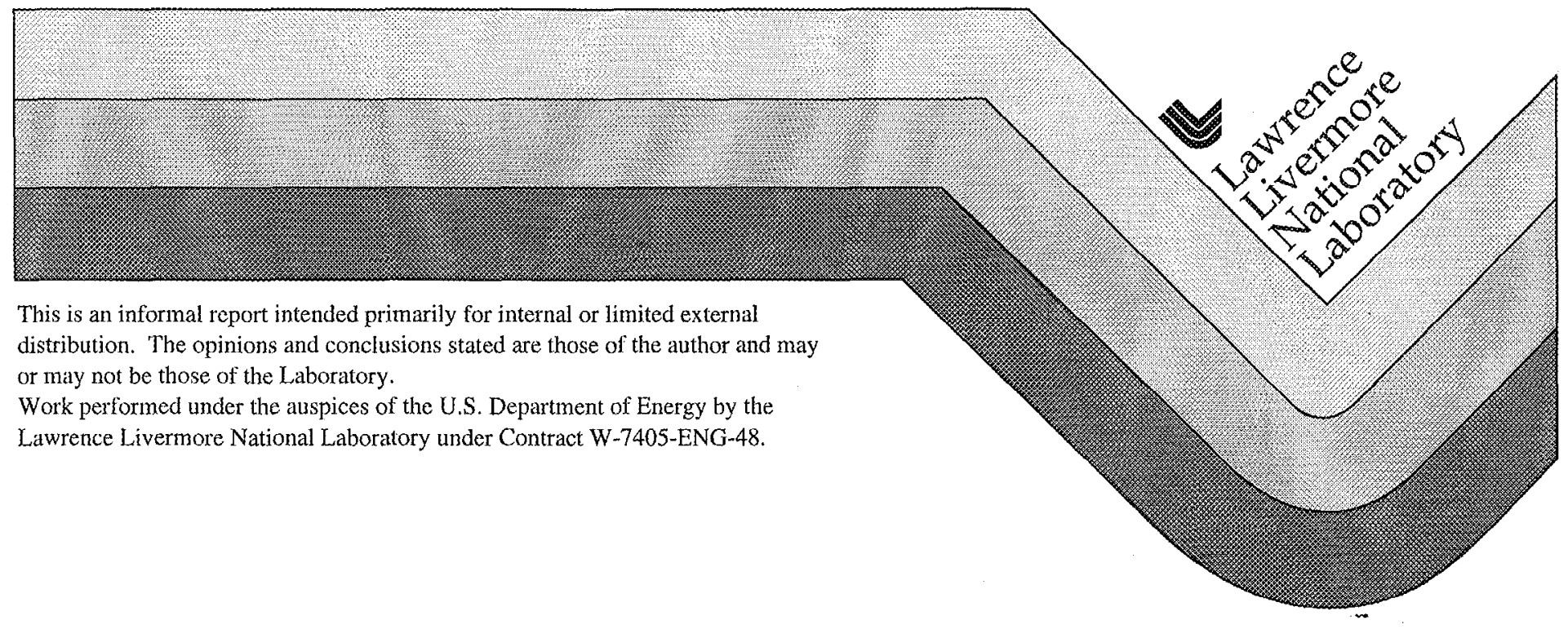




\section{DISCLAIMER}

This document was prepared as an account of work sponsored by an agency of the United States Government. Neither the United States Government nor the University of California nor any of their employees, makes any warranty, express or implied, or assumes any legal liability or responsibility for the accuracy, completeness, or usefulness of any information, apparatus, product, or process disclosed, or represents that its use would not infringe privately owned rights. Reference herein to any specific commercial product, process, or service by trade name, trademark, manufacturer, or otherwise, does not necessarily constitute or imply its endorsement, recommendation, or favoring by the United States Government or the University of California. The views and opinions of authors expressed herein do not necessarily state or reflect those of the United States Government or the University of California, and shall not be used for advertising or product endorsement purposes.

This report has been reproduced directly from the best available copy.

Available to DOE and DOE contractors from the Office of Scientific and Technical Information

P.O. Box 62, Oak Ridge, TN 37831

Prices available from (423) 576-8401

Available to the public from the

National Technical Information Service

U.S. Department of Commerce

5285 Port Royal Rd.,

Springfield, VA 22161 


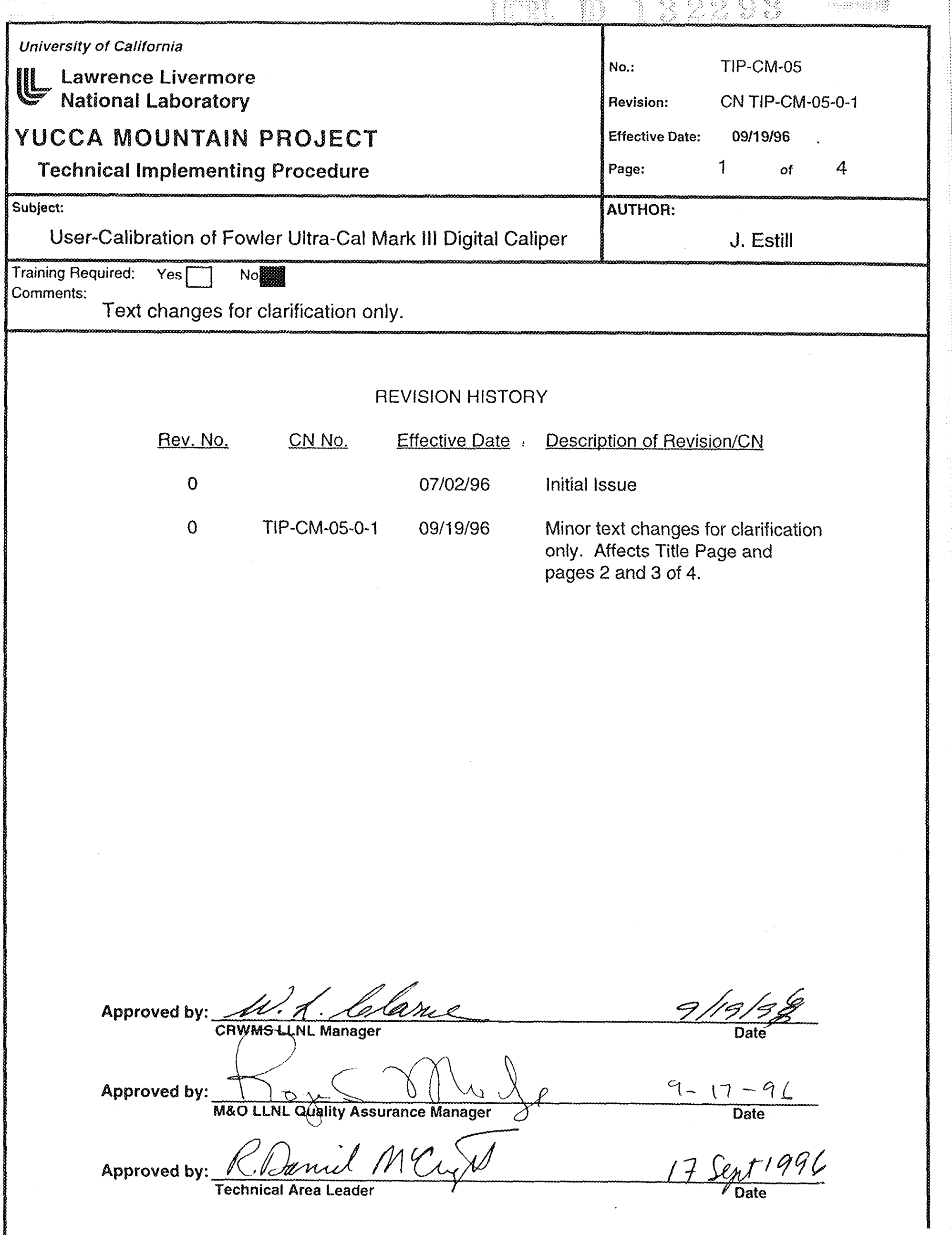


Page:

\subsection{PURPOSE}

The purpose of this technical implementing procedure (TIP) is to describe the procedure that will be employed for user-calibration of a digital caliper used in the determination of specimen dimensions. A caliper is used for some of the activities of the Scientific Investigation Plan (SIP) "Metal Barrier Selection and Testing" (SIP-CM-01, WBS \# 1.2.2.5.1). In particular, it will be used for Activity E-20-50, "Long-Term Corrosion Studies."

\subsection{SCOPE}

This procedure describes the methodology for user calibration of a Fowler Ultra-Cal Mark III digital caliper. National Institutes of Standards and Technology (NIST) traceable gauge blocks are employed in the calibration procedure.

\subsection{RESPONSIBILITIES}

The Principal Investigator (PI) or designee is responsible for the conduct of the activities and methods described in this procedure, and maintaining scientific notebooks and/or electronic recording media.

The Technical Area Leader (TAL) is responsible for verifying that this procedure meets the objectives of the SIP "Metal Barrier Selection and Testing" (SIP CM-01, WBS \#1.2.2.5.1) and its associated Activity Plans.

The YMP Quality Assurance Manager is responsible for monitoring the implementation of this TIP and for assuring the continuing effectiveness of the applicable controls.

\subsection{TEST EQUIPMENT}

A. Fowler Ultra-Cal Mark III Digital Caliper, (serial number 11497) or spare set suitably identified with unique serial number (resolution of 0.001 inches or $0.01 \mathrm{~mm}$ )

B. Fowler English Gauge Blocks with NIST Traceable Standard Certifications. Sandia National Laboratory Standards Laboratory Certificate. Recall No. SNL-2278, date tested: June 13, 1996, expires on: June 13, 1998. (Appendix A)

\subsection{HANDLING OF GAUGE BLOCKS}

A. The user will wear clean cotton gloves when handling the gauge blocks.

B. The user will handle the gauge blocks so as not to damage them.

C. The gauge blocks will be stored in a safe and secure location. 


\begin{tabular}{|c|c|c|c|c|c|}
\hline $\begin{array}{l}\text { No.: } \\
\text { TIP.CM-05 }\end{array}$ & $\begin{array}{l}\text { Revision: } \\
\text { CN TIP-CM-05-0-1 }\end{array}$ & $09 / 19 / 96$ & $\begin{array}{r}\text { Page: } \\
\\
3\end{array}$ & of & 4 \\
\hline
\end{tabular}

\subsection{CALIPER OPERATION}

A. Turning caliper off/on: depress right front button for $>2 \mathrm{sec}$

B. Change caliper mode (Mode $1 \Leftrightarrow$ Mode 2): depress left front button for $>2$ sec

C. Mode 1 (display shows: "mm" or "inch" in lower left and "set" in lower right)

1. zeroing: depress right front button briefly ( $<1 \mathrm{sec}$ ) ("REFy" appears in upper right of display)

2. changing units: depress left front button briefly $(<1 \mathrm{sec})$

D. Mode 2 (display shows: "REFY" in upper left)

1. data transfer to computer: depress left front button briefly $(<1 \mathrm{sec})$

\subsection{CALIBRATION PROCEDURE}

A. Record certified dimensions, including tolerances, of gauge block standards, the calibration certification numbers, the certification date, and any other pertinent information. This information needs only to be entered once into the scientific notebook or electronic database, that is, it is not necessary to enter this information each time the digital calipers are calibrated.

B. Zero the Digital Caliper

\section{Wipe the jaws with a lint-free cloth dipped in isopropanol.}

2. Slide caliper completely to the left until measuring surfaces contact each other.

3. Zero the caliper reading (see section 6.0)

C. Measure calibrated gauge blocks and record the measurements.

Gauge blocks with nominal dimensions close to the specimen dimensions shall be measured.

The following operations shall be repeated for each gauge block:

Open the calipers nominally 0.5 inches greater than the gauge block to be measured. With surfaces of gauge block perpendicular to the caliper measuring, slide the calipers to the left until they contact the specimen. Record the measurement.

\subsection{FREQUENCY OF CALIBRATION}

The caliper will be calibrated by a user prior to obtaining measurements of a specimen or a set of specimens.

A rechecking of the caliper calibration shall be performed at completion of each set of measurements. 
No.:

\subsection{OUT OF CALIBRATION}

Out of calibration equipment will be handled as specified by QP 12.0, "Control of Measuring and Test Equipment". If there is a drift of the measured readings of the gage blocks of more than \pm .002 inches, then the digital caliper cannot be used for this activity until they are repaired and read within the acceptable range ( \pm 0.002 inches).

\subsection{TRAINING}

Personnel responsible for the measurement of test specimens in the applicable activities of SIP "Metal Barrier Selection and Testing" (SIP-CM-01, WBS \# 1.2.2.5.1) shall be trained to this TIP. In particular, this TIP applies to Activity E-20-50, "Long-Term Corrosion Studies."

\subsection{QUALITY ASSURANCE RECORDS}

The following are retained as Quality Assurance records:

- scientific notebook and/or an electronic database (e.g. Microsoft Access)

- the calibration certificates of the NIST traceable standards

- any Nonconformance Reports resulting from calibration

Calibration records governed by this TIP shall be maintained in the scientific notebook and/or appropriate electronic media.

\section{0}

\section{ASSOCIATED ACTIVITY AND TIPS}

This TIP can be used in the activities of the of SIP "Metal Barrier Selection and Testing" (SIP-CM-01, WBS \# 1.2.2.5.1). In particular it may be used in

- Activity E-20-50, "Long Term Corrosion Studies"

- Activity E-20-47, "Thermogravimetric Studies"

Associated TIPs include:

- TIP-CM-04, "User-Calibration of Mettler AT200 Analytical Balance"

- TIP-CM-03, "Electronic Weight-and-Dimensional-Data Entry in a Computer Database"

\subsection{APPENDIX}

Appendix A - Standards Laboratory Certificate for gage blocks

Appendix B - Operating manual of the Fowler Uitra-Cal Mark III Digital Caliper. 


\section{Standards Laboratory Certificate}

English Gage Blocks

Mfgr. Fowler

3 pc. set, .125 to 2 inches

Tested for: LLNL

Date tested: June 13, 1996

Recall No: : SNL-2278

Expires on: June 13, 1998

Serial No.: None

Grade: At

The gage blocks in this set were checked for conformance to Federal Specification

GGG-G -15C. Length and parallelism were checked by mechanical comparison at 68 degrees F. to gage blocks certified by the Primary Standards Laboratory, Sandia National

Laboratories, Albuquerque, New Mexico. A copy of the measured values is attached.

The estimated uncertainties of the measured values are:

Up to and including

1 inch ........... $+1-4$ microinches

2 inch $+/-5$ microinches

The gage blocks in this set are expected to remain within the estimated uncertainty during the calibration interval provided they are not physically damaged.

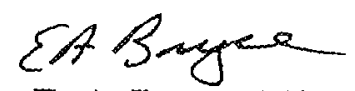

Certified by: E. A. Bryce, 1484-1

Copy to:

Lawrence Livermore National Laboratory

P.O. Box 808

7000 East Ave.

Livermore, California 94550 
MAKE OF SET: Fowier GRADE OF SET: EI

BLOCK SHAPE: ¿quire
SET $S / N:$ SHL-2278

SET SIZE: 3

SET UNITS: inch
DATE: $\quad 05,17,98$

RECAJL HO. SHI

BLOCK MATERIAL: st.e]

deviations \& parallelism in $u$ inches

\begin{tabular}{cccc}
\hline $\begin{array}{c}\text { SBRIAL } \\
\text { HO. }\end{array}$ & $\begin{array}{c}\text { HOGIHAL } \\
\text { SI2B }\end{array}$ & $\begin{array}{c}\text { OQVIA- } \\
\text { TION }\end{array}$ & $\begin{array}{c}\text { PAR. } \\
\text { BRROR }\end{array}$ \\
\hline 9637 & 0.125800 & 0.6 & 0.5 \\
9606 & 1.868000 & 1.5 & 0.5 \\
C649 & 2.080000 & 0.4 & 0.9
\end{tabular}

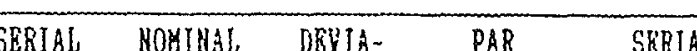

HO. SIRE TION BRROR

SBRIAL HOHIHAL

DEVIA-

TIIVN

PAR.

ERROR

SIZB TION

6043

2.080000

** $2 x$ tol exceeded. * tol. + uno exceeded, * tol exceeded 


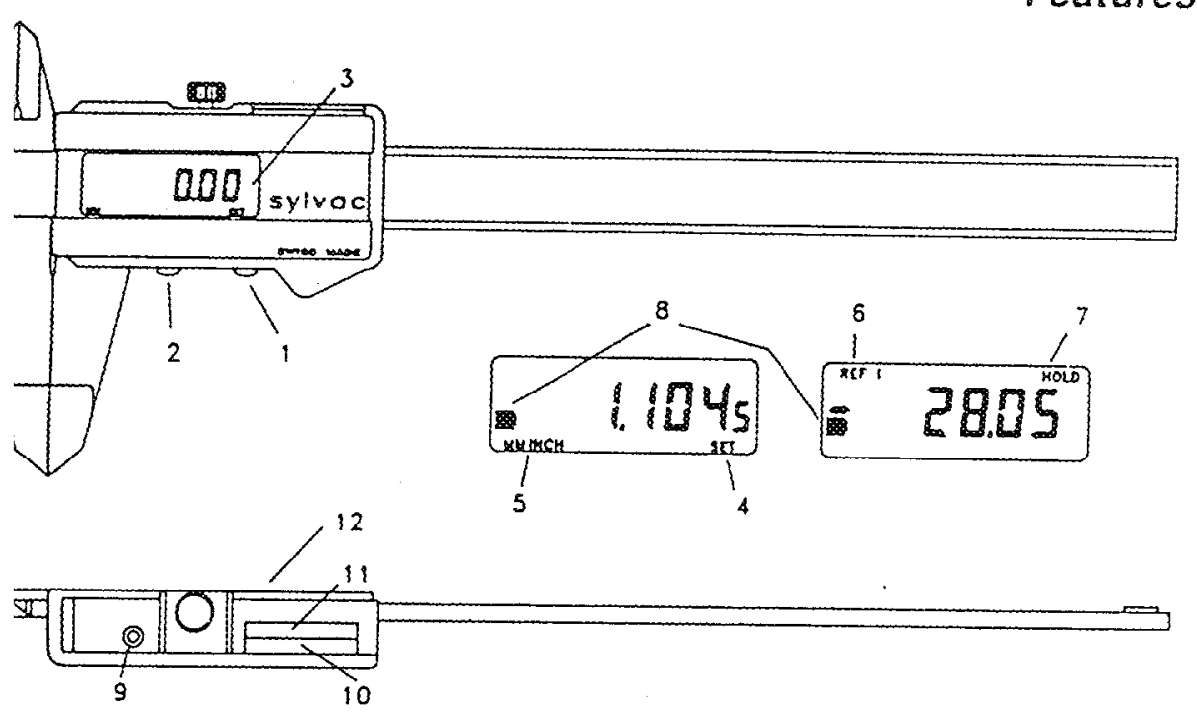

Press-bulton for: ON/OFF, zero selting and memory (HOLD)

Press-bution for: $\mathrm{mm} / \mathrm{inch}$ conversion and mode selection

Combined display:

7. Shows function of button 1

5. Shows function of button 2

3. Indicates mode selected through 2

' Indicates the measurement selected for memory (hold)

3. Portrays termination of battery life

Reset port

Cable connection for RS-232 data output Flip-off" panel for easy battery exchange hort instruction plate

\section{Caliper Ultra-Call Mark III}
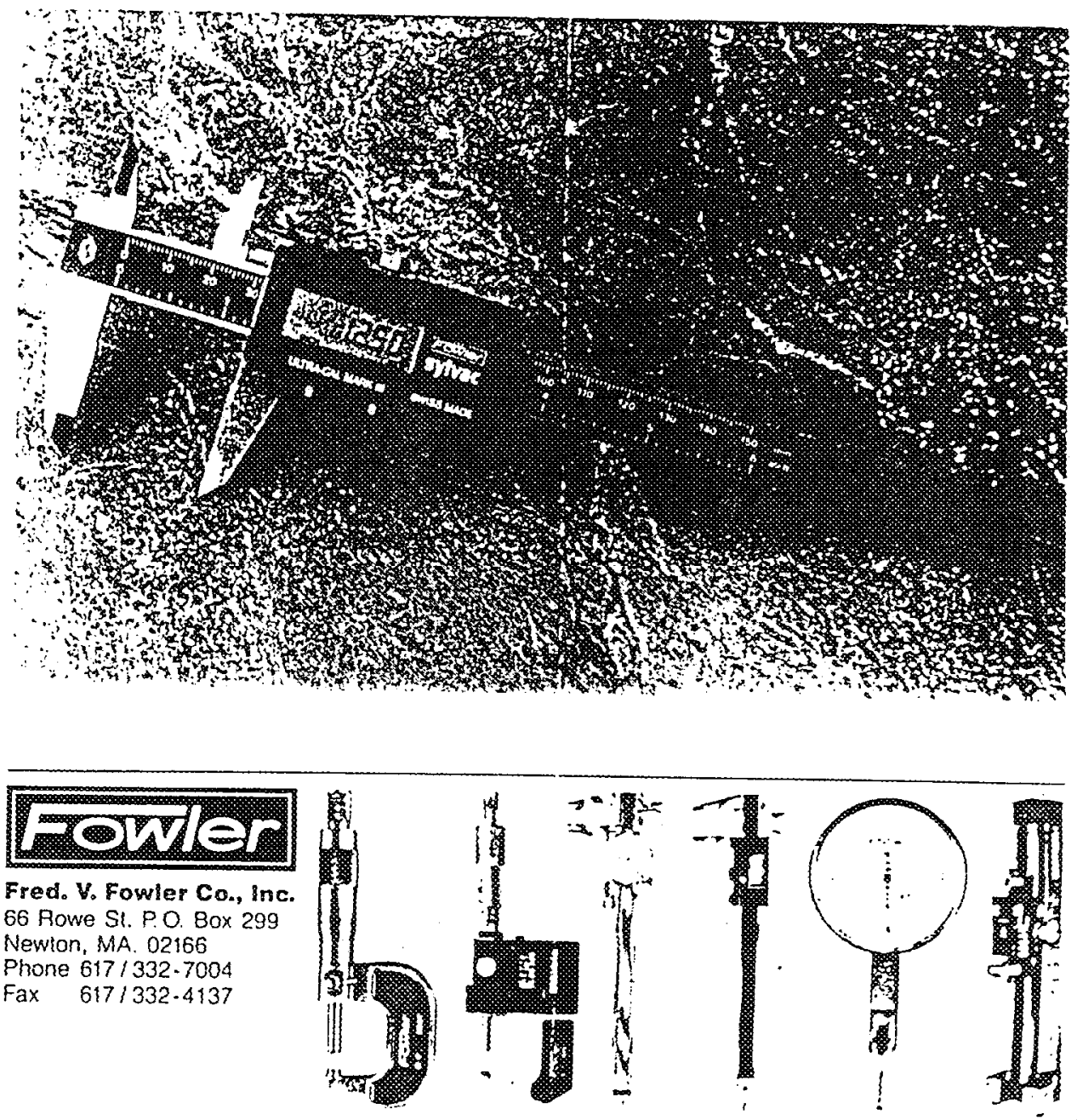


\section{Explanation of instruction plate}

Functions of buttons in mode 2 (red)

(RS-232 output not used)
Beflitions

\section{Technical specifications:}

Measuring range:

Resolution:

Accuracy:

Repeatability:

Operational speed:

Measuring units:

Measuring system:

Display:

Power supply:

Type of batteries:

3attery life:

Norking temperature:

Jutput:

nterface:

ín:

veight:
Internal $\quad 0-150 \mathrm{~mm}, 0-6^{\prime \prime} / 0-200 \mathrm{~mm}, 0-8^{\prime \prime}$

External $0-150 \mathrm{~mm}, 0.6^{\prime \prime} / 0-200 \mathrm{~mm}, 0-8^{\prime \prime}$

$\begin{array}{ll}\text { External } & 0-150 \mathrm{~mm}, 0.6^{\prime \prime} / 0-200 \mathrm{~mm}, 0-8^{\prime \prime} \\ \text { Depth } & 0-150 \mathrm{~mm}, 0.6^{\prime \prime} / 0-200 \mathrm{~mm}, 0.8^{\prime \prime}\end{array}$

$\begin{array}{ll}\text { Depth } & 0-150 \mathrm{~mm}, 0.6 " 10-200 \mathrm{~mm}, 0.8 " \\ \text { Shoulder } & 0-150 \mathrm{~mm}, 0-6 " 10.200 \mathrm{~mm}, 0-8 "\end{array}$

$0.01 \mathrm{~mm} / 0.0005^{\prime \prime}$

$30 \mu \mathrm{m} / 0.001 "$ (Ulira-Call Mark II!/6")

$40 \mu \mathrm{m} / 0.0015^{\prime \prime}$ (Uitra-Call Mark Iil/8")

$10 \mu \mathrm{m} / 0.0005^{\prime \prime}( \pm 2 \mathrm{~s}$ )

$1,5 \mathrm{~m} / \mathrm{sec}$. / $60 " / \mathrm{sec}$.

metric or english (mm/inch), true conversion

capacitive SYLVAC measuring system (patented)

$L C D$, minus sign (-), 6 digils (+ 0.5 mil in inch)

height of digits $6 \mathrm{~mm} / 0.24^{\prime \prime}$

one lithium battery 3V, Type CR2032, capacity: 190 mAh

$\begin{array}{ll}\text { Toshiba CR2032 } & \text { Maxell CR2032 } \\ \text { Renata B/CR2032 } & \text { Sanyo CR2032 } \\ \text { Ucar CR2032 } & \text { Panasonic CR2032 } \\ \text { Rayovac CR2032 } & \text { Varta CR2032 }\end{array}$

2 years when normally used. (2000 work hours per year). When $(B)$ is displayed, the remaining battery life is more than one day.

To protect the environment, please dispose the dead batteries into an appropriate container.

$5^{\circ} \mathrm{C}$ to $40^{\circ} \mathrm{C} / 41$ to 104 degrees $\mathrm{F}$

direct RS232

RS232 compatible interface cable with optoelectronic coupler

hardened and ground stainless steel

$150 \mathrm{~g}$
(Order code: $926.5521 / 2 / 3$ )
Starting the caliper

A brief press of bullon (1) will switch $O N$ the caliper unit.

Having swilched on, the display shows the functions selected prior to switching OFF.

Measuring-functions:

The UItra-Cal Mark III caliper has Iwo distinctive functions:

- Function 1: This is an automatic condition after battery replacement whereby the $\mathrm{mm} / \mathrm{inc}$ selection can be made and a zero selting made al any point

- Function 2: Button (1) allows a memory set (hold) or the transmission of a measured value throus the RS-232 output.

\section{Battery replacement}

"Flip-off" the small panel (10) and (11) on the reverse side of the cover. Remove battery.

When inserting the new battery, ensure that the $(+)$ pole is positioned at the top.

An inverted + pole cannol damage the electronic unil, it simply will not function.

\section{Replace the two small panels and reset the module.}

(Activale the button through reset port [9] with pointed object)

The display will show as described in function 1 with the following result:

Measuring - using function 1 :

- Zero setting:

Press button (1) until the (REF 1) display point (6) appears. Release the button and zero will be displayed:

- Changing the measuring format ( $\mathrm{mm} / \mathrm{inch})$ : Press bulton (2) until the display (e.g. $\mathrm{mm}$ ) is cleared. Release the button and the new formal (e.g. inch) will be displayed.

- Changing the mode:

A prolonged press of button (2) is needed to obtain change of lunction as indicated by $(5,6)$.

\section{Measuring - using function 2}

- Memorizing a (HOLD) value:

A prolonged press of button (1) is needed to oblain the function "HOLD" on the display. The measured value is now retained unlil the "HOLD" is cleared. (Renewed pressing of button (1).

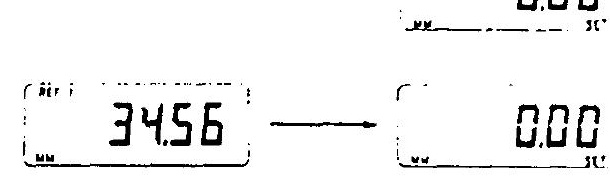

Note: If the caliper is connected to a computer or printer using RS-232 output and the measured valu is transmitted, the HOLD lunction will be cleared.

It is not possible to relurn to function 1 while "HOLD" is displayed.

- Application of button (2):

Only a prolonged press of this button is needed to reset to function 1 .

Switching "OFF" the caliper display unit:

A prolonged press of button (1) will switch "OFF" the display. The actual "set" lunction has n influence.

The original value is retained providing the slide is not displaced. 